\title{
An econometrics method for estimating gold coin futures prices
}

\author{
Fatemeh Pousti $^{\mathrm{a}^{*}}$ and Jamshid Salehi Sadaghiani ${ }^{\mathrm{b}}$
}

\begin{tabular}{l}
\hline A R T I C L E I N F O \\
\hline Article history: \\
Received February 1, 2011 \\
Received in Revised form \\
April, 25, 2011 \\
Accepted 28 April 2011 \\
Available online \\
28 April 2011 \\
\hline Keywords: \\
Econometrics \\
Gold coin futures price \\
Gold price \\
Futures contract \\
Hedging price
\end{tabular}

${ }^{a}$ Faculty of Management Studies and Information Technology(FMIT), Jamia Hamdard University,Newdelhi, India ${ }^{b}$ Department of Management, Allameh Tabatabae University, Tehran, Iran

\begin{abstract}
In this paper, we present two regression functions to estimate gold coin futures price based on gold coin price, foreign exchange rate, price of gold traded globally and trend of time. The proposed model of this paper is used for price estimation of gold coin futures in Iran mercantile exchange (IME).

The proposed model of this paper is applied for historical data of future gold prices and the results are discussed. The preliminary results indicate that an increase on gold coin price could increase gold coin futures price. An increase on foreign exchange price has negative impact on gold coin futures and time horizon has positive impact on gold coin futures on IME.
\end{abstract}

\section{Introduction}

The recent increase in gold price has attracted many investors to look for investment. During the past few years, gold price has hit a new level high, which is bullish indication of buy signal. There are some major factors affecting gold price such as oil price, global uncertainty, inflation, etc. Shafiee and Topal (2010) studied the historical trend of gold prices from January 1968 to December 2008. They proposed a model to estimate gold coin futures prices for the next 10 years based on monthly data of nominal gold price. There are literally many different techniques for estimating gold prices such as moving average, wavelet, etc. Parisi et al. (2008) proposed a method for analyzing recursive and rolling neural models to predict short time gold price and validated their model using block bootstrap technique.

There are also some efforts to use macro econometrics methods to forecast gold price such power GARCH model. Tully and Lucey (2007) used cash and gold coin futures and significant economic variables for a period of 1983 to 2003 to predict gold price changes. They reported that their model provides the most sufficient description for the data, with the inclusion of a GARCH term, free power term and unrestricted leverage effect term. Blose (2010) studied the effects of consumer price index

\footnotetext{
* Corresponding author. Tel. +982188208317

E-mail addresses: fatemeh_pousti@yahoo.com (F. Pousti) 
surprises on gold price and explained that there is no relationship between this macroeconomic term and gold price movements. Batten et al. (2010) investigated the effects of macroeconomic factors such as business cycle, monetary environment and financial market conditions on gold price movements and confirmed that gold price could be a function of these items but other precious metals such as silver had no meaningful relationship with macroeconomic factors.

Mamon et al. (2008) studied the optimal filtering of log returns of commodity prices where the mean and volatility are formulated based on hidden Markov chain with finite state space. They used their method on a set of high frequency gold price data between the years of 1973 to 2006 and analyzed the $h$-step ahead price forecasts against the Diebold-Kilian metric. They reported that a two-state hidden Markov model can describe the dynamics of the data and the gold price can be predicted in the short term but almost impossible to predict in the long term. There are some evidences to believe that recent increase on gold price may have some relationship with oil price. Zhang and Wei (2010) performed an investigation on the crude oil and gold market and reported a relatively positive impact of oil upward price on gold price. Although there are many micro and macroeconomic parameters affecting gold prices but there are also some psychological barriers on gold price. Aggarwal and Lucey (2007) are believed to be the first who studied the existence of psychological obstacles in a variety of daily and intra-day gold price historical data.

In this paper, we propose two econometrics method to predict the gold coins futures price traded in IME based on different macroeconomic factors. The organization of this paper is as follows. We first study the trend of gold market in different cycles and present the mathematical model in section 2. The results and discussions are presented in section 3 and concluding remarks are given in section 4 to summarize the contribution of this paper.

\section{The gold market}

There are different commodity markets in the world for buying and selling precious metals such as gold and silver but these markets are not open to all people in the world. In some countries gold is traded in various forms such jewelry and coins. Coins play important role on gold market for many middle-east countries such as Iran. There are different types of gold coins traded in Iran, offered by the government in various sizes in grams. Until recently, there were no future market for trading gold in Iran but since 2008, government initiated new regulations for gold coin futures market. Commodity futures are agreements of contracts utilized to purchase or sell a specified amount of a given commodity. The agreement will commit the buyer and the seller to a fixed price that will be in effect on a specified future date. When this future date arrives, the buyer is expected to have paid the agreed upon price for the futures, and the seller will have delivered ownership of the commodities to the buyer.

During the long discussions in the Shariah board of the securities \& exchange organization (SEO), with the presence of clergymen, financial and economic experts, it was suggested to use the model of "commitment to buy against commitment to sell" in a specific time in the future. By this, the doubt of Kali Bi-l-Kali Sale (bay al-kali bi al-kali: deferment of both counter values to a future date turns futures sales into the sale of one debt for another which is forbidden by Islam) would be removed. Other jurisprudential doubts such as Akl-Al-Mal Bi-l-Batil(akl-al-mal bi-l-batil: devouring of the property of others, it is the same as gambling, which is clearly forbidden) were also removed by some specific corrections. Another problem with conventional futures contracts was that the values of lunched futures contracts are several times greater than the real asset available. Also, it was decided to establish a direct control on the value of lunched futures contracts to remove the problem of superficial transactions and prevent the irregular and superficial growth of the value of futures contracts in the Islamic capital market. For Islamic capital market in Iran, few restrictions are prescribed for each dealer, broker and the whole market to prevent an irregular growth in the value of futures contracts in comparison with the value of underlying assets. Now, Islamic futures are put into 
action in Iran and some commodities such as gold bar, copper bar and gold coins have already been set as the underlying assets. SEO is developing the futures contracts for some other commodities such as, petrochemical products, oil and oil products, agricultural products, metals, and securities.

It's a fairly safe bet that as the delivery month of a futures contract approaches, the future's price will generally inch toward or even come to equal the spot price as time progresses. This is a very strong trend that happens regardless of the contract's underlying asset. Arbitrage and the law of supply and demand can easily explain this convergence. The maturity of gold coin futures contracts is each even month according to Jalali (Persian) Calendar in IME. The gold coin futures are at the nascent stage in Iran, having this point in mind the ultimate end of this research is to design a model to predict gold coin futures price in Iran mercantile exchange (IME). We identify the influence of four major factors, as independent variables, on gold coin futures price; dependent variable (GCF) and study the trend of each of independent variables and gold coin futures for each interval. These four variables which are: 1. The underlying asset; Iran Azadi Gold Coin (GC), 2. Time horizon (t), 3. Global gold; price of global gold per each ounce (GG), and foreign exchange rate (FX); the equality rate of the US Dollar to Iran currency; Iranian Rial(IRR). The description of all of variables (Mean, median, mode, standard deviation, maximum rate and minimum rate) will be explained. In this paper we look to find appropriate answers for two major questions. First, we want to find out how correlated gold coin futures price and Iran azadi gold coin price move towards each other during November 2008 till March 2010 which is the gold coin futures life time. Second, we would like to know how correlated gold coin futures price and Global gold price move towards each other during November 2008 till March 2010. We also wish to know how correlated gold coin futures price and foreign exchange rate move towards each other during November 2008 till March 2010. The following hypothesis is built to answer the main questions of this research.

$\begin{cases}H_{0}: & \text { There is no significant correlation between each of variables (GC, GG, GCF, and FOREX) } \\ H_{1}: & \text { There is a significant correlation between each of variables (GC, GG, GCF, and FOREX) }\end{cases}$

There were nine sets of contracts for the period of our study and the study of this paper investigates each contract, separately.

\section{Results}

As we explained there were nine three-month-old contracts held for the period of the study. Table 1 summarizes different statistical observations for all these contracts. According to Table 1, the gold coin price in the first futures transaction period has the mean of IRR.2250000 in the Iran spot market. The median also is IRR.2250000. The gold coin price has the mode of IRR.2250000 during the first transaction period. The standard deviation is equal to IRR.27640. The maximum price during this period is IRR.2300000 and the minimum price is IRR.2200000. The gold coin price in the second futures transaction period has the mean of IRR.2200000 in the Iran spot market. The median also is IRR.220000. The gold coin price has the mode of IRR.2210000 during this period. The standard deviation is equal to IRR.43180.The maximum price during this period is IRR.2290000 and the minimum price is IRR.2140000. According to results of bivariate correlation measure the null hypothesis is rejected in favor of the alternative hypothesis in majority of cases. Consequently the dependent variable (gold coin futures price) and all independent variables (Iran azadi gold coin price, global gold price and equality rate of us dollar to Iran currency) are highly correlated in majority of transaction periods. Therefore, all independent variables are used as predictors to anticipate the expected value of dependent variable. 
Table 1

Statistical observations for four independent variables

\begin{tabular}{|c|c|c|c|c|c|c|c|c|c|c|c|}
\hline \multicolumn{11}{|c|}{ Futures Transaction Periods } & \multirow[b]{2}{*}{ P-Value } \\
\hline & able & 1 & 2 & 3 & 4 & 5 & 6 & 7 & 8 & 9 & \\
\hline \multirow{6}{*}{ GC } & Mean & $2.25 \mathrm{E} 6$ & $2.20 \mathrm{E} 6$ & $2.20 \mathrm{E} 6$ & $2.18 \mathrm{E} 6$ & $2.24 \mathrm{E} 6$ & $2.38 \mathrm{E} 6$ & $2.69 \mathrm{E} 6$ & $2.67 \mathrm{E} 6$ & $2.68 \mathrm{E} 6$ & \multirow{6}{*}{$\mathrm{P}>0.05$} \\
\hline & Median & 2.25E6 & 2.20E6 & 2.18E6 & 2.18E6 & 2.25E6 & 2.34E6 & 2.68E6 & 2.67E6 & 2.68E6 & \\
\hline & Mode & 2250000 & 2210000 & 2170000 & 2160000 & 2250000 & 2260000 & 2520000 & 2680000 & 2680000 & \\
\hline & SD & 2.764E4 & 4.318E4 & 3.882E4 & 2.837E4 & 3.853E4 & $1.345 \mathrm{E} 5$ & 9.905E4 & $6.344 \mathrm{E} 4$ & $2.080 \mathrm{E} 4$ & \\
\hline & Min & 2200000 & 2140000 & 2150000 & 2140000 & 2150000 & 2230000 & 2510000 & 2460000 & 2640000 & \\
\hline & Max & 2300000 & 2290000 & 2290000 & 2250000 & 2340000 & 2710000 & 2860000 & 2830000 & 2715000 & \\
\hline \multirow{6}{*}{ GG } & Mean & $8.20 \mathrm{E} 5$ & 7.39E5 & $5.51 \mathrm{E} 5$ & 5.85E5 & $6.29 \mathrm{E} 5$ & $6.68 \mathrm{E} 5$ & 7.98E5 & 7.73E5 & $7.40 \mathrm{E} 5$ & \multirow{6}{*}{$\mathrm{P}>0.05$} \\
\hline & Median & $8.11 \mathrm{E} 5$ & $7.22 \mathrm{E} 5$ & $5.16 \mathrm{E} 5$ & 6.36E5 & $6.42 \mathrm{E} 5$ & $6.75 E 5$ & 8.09E5 & 7.89E5 & $7.40 \mathrm{E} 5$ & \\
\hline & Mode & 795152 & $676111^{a}$ & $416892^{\mathrm{a}}$ & $416892^{a}$ & $568599^{a}$ & $568599^{a}$ & $680182^{\mathrm{a}}$ & $688013^{a}$ & $719236^{a}$ & \\
\hline & SD & $3.540 \mathrm{E} 4$ & $5.964 \mathrm{E} 4$ & $1.038 \mathrm{E} 5$ & 8.742E4 & 4.053E4 & $6.792 \mathrm{E} 4$ & 5.099E4 & $5.134 \mathrm{E} 4$ & $2.054 \mathrm{E} 4$ & \\
\hline & Min & 775684 & 641763 & 416892 & 416892 & 555883 & 555103 & 649952 & 678931 & 700323 & \\
\hline & Max & 891312 & 844718 & 778193 & 708509 & 708509 & 828432 & 876929 & 876929 & 783600 & \\
\hline \multirow{6}{*}{ GCF } & Mean & $2.00 \mathrm{E} 6$ & 2.07E6 & $2.14 \mathrm{E} 6$ & $2.15 \mathrm{E} 6$ & $2.22 \mathrm{E} 6$ & $2.38 \mathrm{E} 6$ & $2.76 \mathrm{E} 6$ & $2.72 \mathrm{E} 6$ & $2.76 \mathrm{E} 6$ & \multirow{6}{*}{$\mathrm{P}>0.05$} \\
\hline & Median & 2.00E6 & 2.06E6 & 2.14E6 & 2.13E6 & 2.23E6 & 2.34E6 & 2.70E6 & 2.70E6 & 2.76E6 & \\
\hline & Mode & 2.E6 ${ }^{\mathrm{a}}$ & 2014000 & 2.E6 ${ }^{\mathrm{a}}$ & 2.E6 ${ }^{\mathrm{a}}$ & 2.E6 ${ }^{\mathrm{a}}$ & 2214989 & 3.E6 ${ }^{\mathrm{a}}$ & 2719000 & 2725750 & \\
\hline & SD & $1.483 \mathrm{E} 4$ & $5.540 \mathrm{E} 4$ & 3.379E4 & 3.885E4 & 4.209E4 & 1.604E5 & 1.727E5 & $1.066 \mathrm{E} 5$ & $1.810 \mathrm{E} 4$ & \\
\hline & Min & 1970000 & 2003500 & 2090000 & 2087723 & 2133000 & 2214989 & 2525357 & 2528048 & 2725750 & \\
\hline & Max & 2032000 & 2205308 & 2239923 & 2238852 & 2326302 & 2740000 & 3098136 & 3082000 & 2780095 & \\
\hline \multirow{6}{*}{$\mathrm{FX}$} & Mean & 9948.06 & 9783.40 & 9876.64 & 9847.38 & 9884.93 & 9912.95 & 9951.15 & 9994.69 & 9986.23 & \multirow{6}{*}{$\mathrm{P}>0.05$} \\
\hline & Median & 9948.00 & 9800.00 & 9891.00 & 9860.00 & 9918.00 & 9913.00 & 9945.00 & $1.00 \mathrm{E} 4$ & $1.00 \mathrm{E} 4$ & \\
\hline & Mode & 10104 & 9800 & 9874 & 9598 & $9917^{\mathrm{a}}$ & 9939 & 10004 & $10000^{\mathrm{a}}$ & 9901 & \\
\hline & SD & 125.809 & 145.167 & 117.607 & 131.557 & 103.568 & 31.668 & 39.061 & 33.873 & 56.111 & \\
\hline & Min & 9782 & 9560 & 9578 & 9598 & 9598 & 9828 & 9878 & 9901 & 9866 & \\
\hline & Max & 10123 & 9996 & 10096 & 10096 & 9980 & 9980 & 10017 & 10052 & 10052 & \\
\hline
\end{tabular}

3.1. The correlation of Iran Azadi gold coin (GC) and global gold (GG)

The correlation of the global gold prices and the Iran Azadi gold coin is 0.584. Since the P-value is less than the significance level (P-value<.05), correlation of two variables is significantly different with zero. The null hypothesis is rejected in favor of the alternative hypothesis. As a result, the underlying asset (Iran Azadi Gold Coin) and the global gold are significantly correlated.

3.2. The correlation of Iran Azadi gold coin (GC) and foreign exchange (FX)

The correlation of the Iran azadi gold coin price and the equality rate of US Dollar to Iran currency is .451. Since the P-value is less than the significance level (P-value $<.05)$, the correlation of two variables is significantly different with zero. It means that the null hypothesis is rejected in favor of the alternative hypothesis. As a result the Iran azadi gold coin price and the equality rate of US Dollar to Iran currency are significantly correlated.

\subsection{The correlation between Iran Azadi gold coin price and gold coin futures}

Now there is another question as how the gold coin futures price is correlated with the Iran Azadi gold coin price for the contracts held between the November 2008 till March 2010. To answer this question, we perform the study the correlations between gold coin and gold coin future. Fig. 1a to Fig. 1i show the correlation between these two variables for the first to ninth contracts, respectively.

\subsubsection{The correlation of Iran Azadi gold coin price and gold coin futures in the first transaction period} The correlation of gold coin futures price and the Iran Azadi gold coin is .51. Since the P-value is less than the significance level (P-value $<.05$ ), correlation of two variables is significantly different with zero. The null hypothesis is rejected in favor of the alternative hypothesis. As a result the Iran Azadi gold coin price and gold coin futures price are significantly correlated in first period.

3.3.2 The correlation of Iran Azadi gold coin price and gold coin futures in the second transaction period The correlation of gold coin futures price and the gold coin price is .384.Since the P-value is greater than the significance level (P-value>.05), Correlation of two variables is close to zero. The null hypothesis cannot be rejected in favor of the alternative hypothesis. 


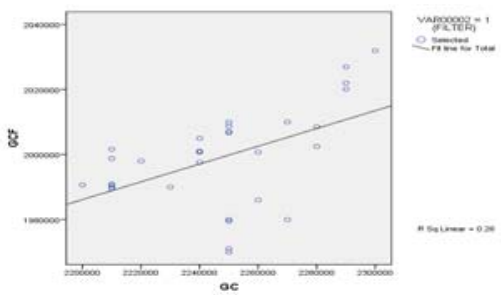

(a)

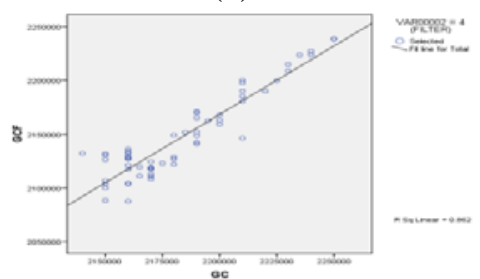

(d)

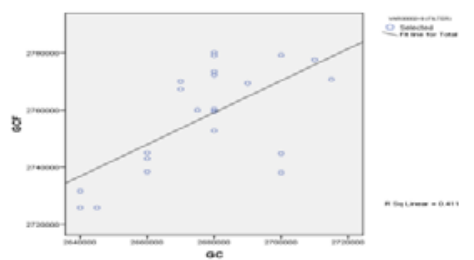

(g)

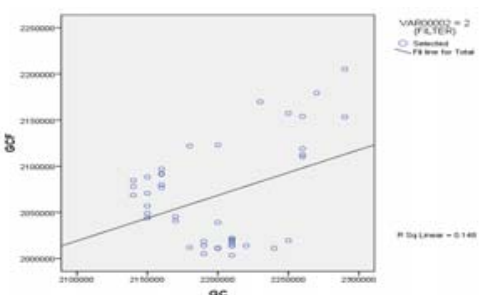

(b)

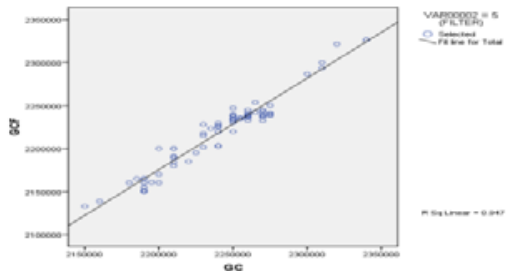

(e)

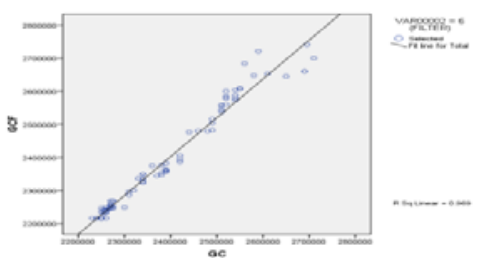

(h)

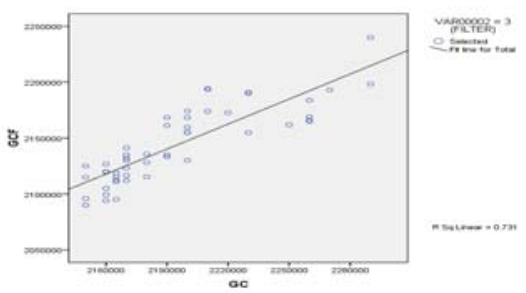

(c)

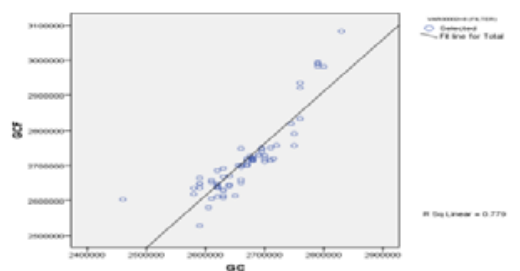

(f)

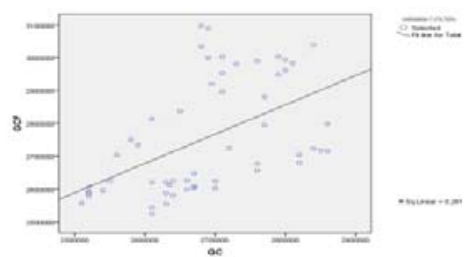

(i)

Fig. 1. The correlation

3.3.3 The correlation of Iran Azadi gold coin price and gold coin futures in the third transaction period The correlation of the gold coin futures and the underlying asset is 0.855 . Since the P-value is less than the significance level (P-value<.05), correlation of the gold coin futures and the Iran Azadi Gold Coin is significantly different with zero. The null hypothesis is rejected in favor of the alternative hypothesis. As a result the Iran Azadi gold coin price and gold coin futures price are significantly correlated in third period. The simple scatter diagram shows the direct linear relationship of two variables. Because the data points are relatively close to the fit line, it is understood that there is a high degree of association between the Iran Azadi gold coin price and gold coin futures price in third period.

3.3.4 The correlation of Iran Azadi gold coin price and gold coin futures in the fourth transaction period The correlation of the gold coin futures and the underlying asset is 0.928. Since the P-value is less than the significance level (P-value $<.05$ ), correlation of two variables is significantly different with zero. The null hypothesis is rejected in favor of the alternative hypothesis. As a result the Iran Azadi gold coin price and gold coin futures price are significantly correlated in fourth period. The simple scatter diagram shows the direct linear relationship of two variables. Because the data points are relatively close to the fit line, it is understood that there is a high degree of association between the Iran Azadi gold coin price and gold coin futures price in fourth period.

\subsubsection{The correlation of Iran Azadi gold coin price and gold coin futures in the fifth transaction period}

The correlation of the gold coin futures and the underlying asset is 0.973 . Since the P-value is less than the significance level (P-value<.05), correlation of two variables is significantly different with zero. The null hypothesis is rejected in favor of the alternative hypothesis. As a result the Iran Azadi gold coin price and gold coin futures price are significantly correlated in fifth period. The simple scatter diagram shows the direct linear relationship of two variables. Because the data points are relatively close to the fit line, it is understood that there is a high degree of association between the Iran Azadi gold coin price and gold coin futures price in fifth period.

\subsubsection{The correlation of Iran Azadi gold coin price and gold coin futures in the sixth transaction period}


The correlation of the gold coin futures and the underlying asset is 0.984 . Since the P-value is less than the significance level (P-value $<.05$ ), correlation of two variables is significantly different with zero. The null hypothesis is rejected in favor of the alternative hypothesis. As a result the Iran Azadi gold coin price and gold coin futures price are significantly correlated in sixth period. The simple scatter diagram shows the direct linear relationship of two variables. Because the data points are relatively close to the fit line, it is understood that there is a high degree of association between the Iran Azadi gold coin price and gold coin futures price in sixth period.

\subsubsection{The correlation of Iran Azadi gold coin price and gold coin futures in the seventh transaction period} The correlation of the gold coin futures and the underlying asset is 0.511 . Since the P-value is less than the significance level (P-value $<.05$ ), correlation of two variables is significantly different with zero. The null hypothesis is rejected in favor of the alternative hypothesis. As a result the Iran Azadi gold coin price and gold coin futures price are significantly correlated in seventh period.

\subsubsection{The correlation of Iran Azadi gold coin price and gold coin futures in the eight transaction period} The correlation of the gold coin futures and the underlying asset is 0.883 . Since the P-value is less than the significance level (P-value $<.05$ ), correlation of two variables is significantly different with zero. The null hypothesis is rejected in favor of the alternative hypothesis. As a result the Iran Azadi gold coin price and gold coin futures price are significantly correlated in eighth period.

3.3.9 The correlation of Iran Azadi gold coin price and gold coin futures in the ninth transaction period The correlation of the gold coin futures and the underlying asset is 0.641 . Since the P-value is less than the significance level (P-value<.05), correlation of two variables is significantly different with zero. The null hypothesis is rejected in favor of the alternative hypothesis. As a result, the Iran Azadi gold coin price and gold coin futures price are significantly correlated in ninth period. In summary, we can conclude that the gold coin futures price and the Iran Azadi gold coin have correlated movement in majority (eight out of nine) of transaction periods. Here, the alternative hypothesis, which indicates that there is a significant correlation between GC and GCF is confirmed by the result of bivariate correlation measure in the eight transaction periods.

\subsection{The relationship between gold coin futures prices and global gold prices}

The second question is find out how the Gold coin futures prices and global gold prices are correlated from November 2008 to March 2010. Fig. 2a to Fig. 2i show the correlation of these two variables.

\subsubsection{The correlation of global gold and gold coin futures for the first transaction period} The correlation of gold coin futures price and the global gold is .14. Since the P-value is greater than the significance level (P-value>.05), correlation of two variables is close to zero. The null hypothesis cannot be rejected in favor of the alternative hypothesis.

\subsubsection{The correlation of global gold and gold coin futures for the second transaction period}

The correlation of gold coin futures price and the global gold is -.51. Since the P-value is less than the significance level (P-value<.05), correlation of two variables is significantly different to zero. The null hypothesis is rejected in favor of the alternative hypothesis. As a result the gold coin futures price and the global gold price are negatively correlated.

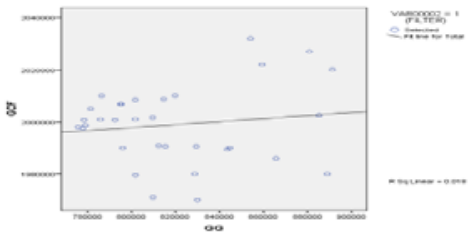

(a)

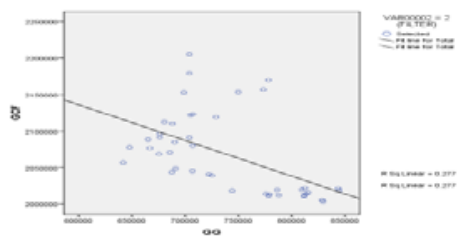

(b)

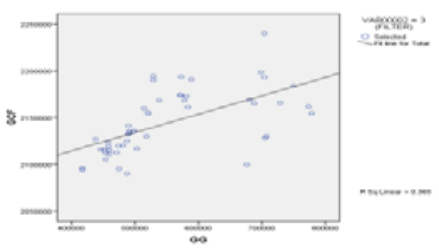

(c) 


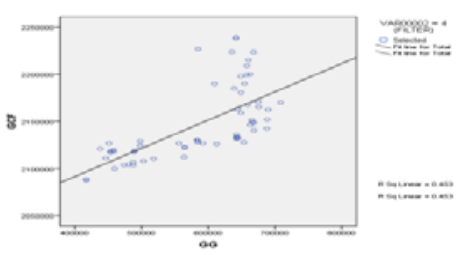

(d)

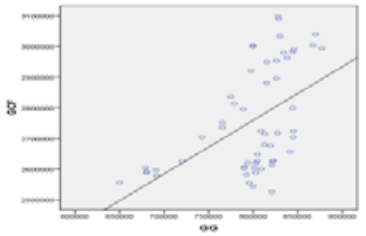

(g)

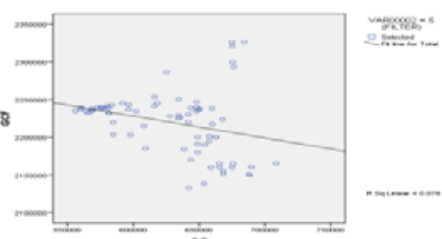

(e)

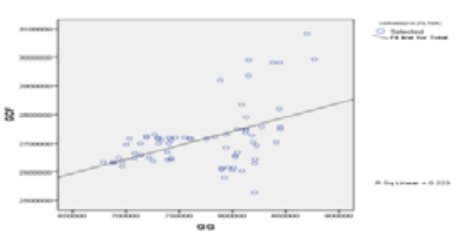

(h)

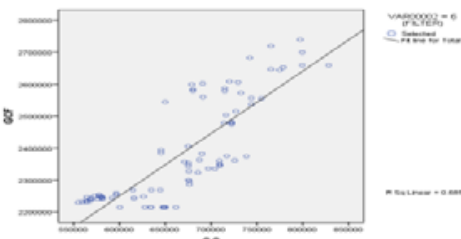

(f)

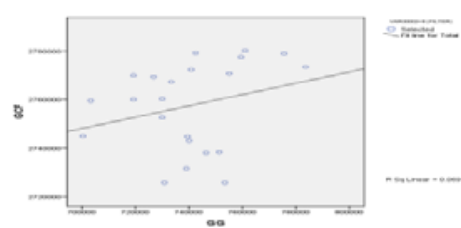

(i)

Fig. 2 The correlation plot for GC and GCF

3.4.3 The correlation of global gold and gold coin futures for the third transaction period The correlation of the gold coin futures and the underlying asset is 0.855 . Since the P-value is less than the significance level (P-value $<.05$ ), correlation of two variables is significantly different with zero. The null hypothesis is rejected in favor of the alternative hypothesis. As a result the global gold price and gold coin futures price are significantly correlated in third period.

3.4.4 The correlation of global gold and gold coin futures for the fourth transaction period The correlation of the gold coin futures and the underlying asset is 0.673 . Since the P-value is less than the significance level (P-value $<.05$ ), correlation of two variables is significantly different with zero. The null hypothesis is rejected in favor of the alternative hypothesis. As a result the global gold price and gold coin futures price are significantly correlated in fourth period.

3.4.5 The correlation of global gold and gold coin futures for the fifth transaction period

The correlation of the gold coin futures and the underlying asset is -0.279 . Since the P-value is less than the significance level (P-value $<.05$ ), correlation of two variables is significantly different with zero. The null hypothesis is rejected in favor of the alternative hypothesis. As a result the global gold price and gold coin futures price are significantly correlated in fifth period.

\subsubsection{The correlation of global gold and gold coin futures for the sixth transaction period}

The correlation of the gold coin futures and the global gold is 0.828 . Since the P-value is less than the significance level (P-value<.05), correlation of two variables is significantly different with zero. The null hypothesis is rejected in favor of the alternative hypothesis. As a result the global gold price and gold coin futures price are significantly correlated in sixth period.

\subsubsection{The correlation of global gold and gold coin futures for the seventh transaction period}

The correlation of the gold coin futures and the global gold is 0.516. Since the P-value is less than the significance level (P-value<.05), correlation of two variables is significantly different with zero. The null hypothesis is rejected in favor of the alternative hypothesis. As a result the global gold price and gold coin futures price are significantly correlated in seventh period.

\subsubsection{The correlation of global gold and gold coin futures for the eighth transaction period}

The correlation of the gold coin futures and the global gold is 0.472 . Since the P-value is less than the significance level (P-value $<.05)$, correlation of two variables is significantly different with zero. The null hypothesis is rejected in favor of the alternative hypothesis. As a result the global gold price and gold coin futures price are significantly correlated in eighth period.

\subsubsection{The correlation of global gold and gold coin futures for the ninth transaction period}


The correlation of the gold coin futures and the global gold is 0.263 . The P-value is greater than the significance level (P-value<.05).The null hypothesis cannot be rejected in favor of the alternative hypothesis.

In summary we can conclude that the gold coin futures price and global gold price have correlated movement in the majority of transaction periods (Six transaction periods). Here, the alternative hypothesis (There is a significant correlation between GG and GCF) is confirmed by the result of bivariate correlation measure in six transaction periods. It is interpreted that the global gold price is one of the determinant variables to predict the gold coin futures price.

\subsection{The correlation between the gold coin future prices and foreign exchange rate}

The third question is to study the correlation between the gold coin futures prices and foreign exchange rate move from November 2008 to March 2010. Fig. 3a to Fig. 3i show these relationships for contract one to nine, respectively.

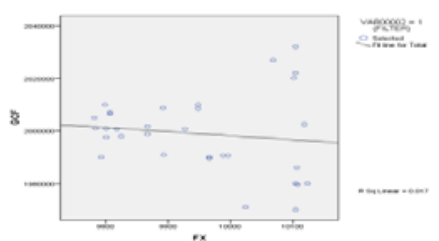

(a)

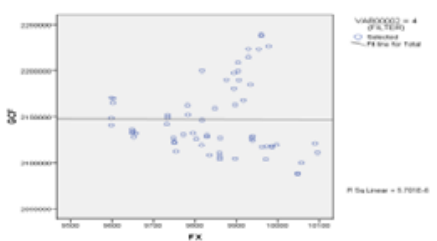

(d)

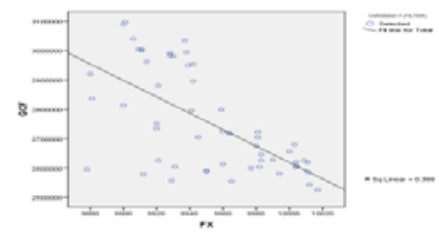

(g)

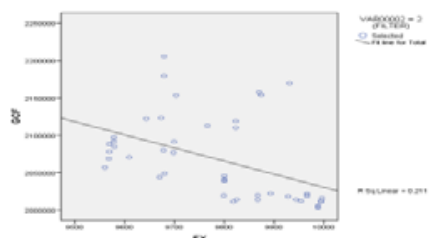

(b)

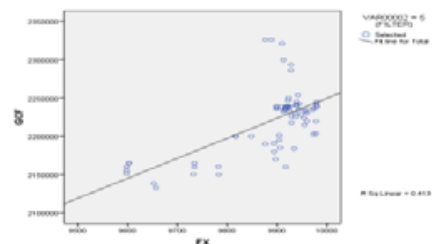

(e)

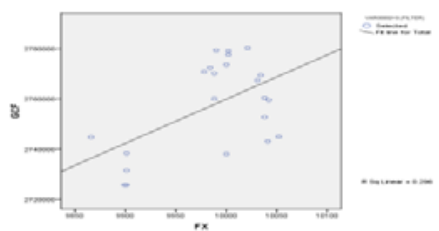

(h)

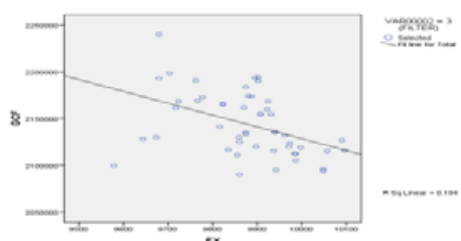

(c)

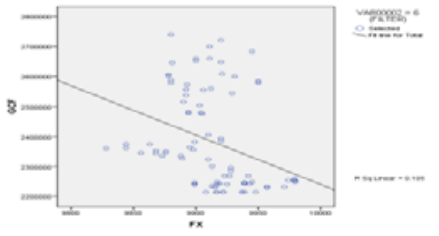

(f)

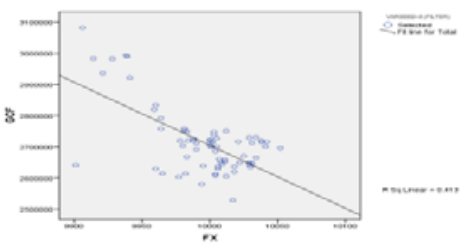

(i)

Fig. 3. The correlation between the gold coin future prices and foreign exchange rate

3.5.1 The correlation between the GCF prices and foreign exchange rate for the first transaction period The correlation of gold coin futures price and the foreign exchange rate is -.13. Since the P-value is greater than the significance level (P-value>.05), correlation of two variables is close to zero. The null hypothesis cannot be rejected in favor of the alternative hypothesis.

3.5.2 The correlation between the GCF prices and foreign exchange rate for the second transaction period The correlation of gold coin futures price and the foreign exchange rate is .459. Since the P-value is less than the significance level (P-value $<.05)$, correlation of two variables is significantly different to zero. The null hypothesis is rejected in favor of the alternative hypothesis. As a result the foreign exchange rate and gold coin futures price are significantly correlated in second period.

3.5.3 The correlation between the GCF prices and foreign exchange rate for the third transaction period The correlation of gold coin futures price and the foreign exchange rate is -0.44 . Since the P-value is less than the significance level (P-value $<.05)$, correlation of two variables is significantly different to zero. The null hypothesis should is rejected in favor of the alternative hypothesis. As a result the foreign exchange rate and gold coin futures price are significantly correlated in third period. 
3.5.4 The correlation between the GCF prices and foreign exchange rate for the fourth transaction period The correlation of gold coin futures price and the foreign exchange rate is -0.002 . Since the P-value is greater than the significance level ( $\mathrm{P}$-value $>.05$ ), correlation of two variables is significantly different to zero. The null hypothesis cannot be rejected in favor of $t$ alternative hypothesis.

3.5.5 The correlation between the GCF prices and foreign exchange rate for the fifth transaction period The correlation of gold coin futures price and the foreign exchange rate is .643. Since the P-value is less than the significance level (P-value $<.05)$, correlation of two variables is significantly different to zero. The null hypothesis is rejected in favor of the alternative hypothesis.

3.5.6 The correlation between the GCF prices and foreign exchange rate for the sixth transaction period The correlation of gold coin futures price and the foreign exchange rate is -.324 Since the P-value is less than the significance level (P-value $<.05)$, correlation of two variables is significantly different to zero. The null hypothesis is rejected in favor of the alternative hypothesis. As a result the foreign exchange rate and gold coin futures price are significantly correlated in sixth period.

3.5.7 The correlation between the GCF prices and foreign exchange rate for the seventh transaction period The correlation of gold coin futures price and the foreign exchange rate is -.632 Since the P-value is less than the significance level (P-value $<.05)$, correlation of two variables is significantly different to zero. The null hypothesis is rejected in favor of the alternative hypothesis. As a result the foreign exchange rate and gold coin futures price are significantly correlated in seventh period.

3.5.8 The correlation between the GCF prices and foreign exchange rate for the eighth transaction period The correlation of gold coin futures price and the foreign exchange rate is -.632 Since the P-value is less than the significance level ( $\mathrm{P}$-value $<.05)$, correlation of two variables is significantly different to zero. The null hypothesis is rejected in favor of the alternative hypothesis. As a result the foreign exchange rate and gold coin futures price are significantly correlated in eighth period.

3.5.9 The correlation between the GCF prices and foreign exchange rate for the ninth transaction period The correlation of gold coin futures price and the foreign exchange rate is .544 since the P-value is less than the significance level (P-value $<.05)$, correlation of two variables is significantly different to zero. The null hypothesis is rejected in favor of the alternative hypothesis. As a result the foreign exchange rate and gold coin futures price are significantly correlated in ninth period.

In summary, we can conclude that the gold coin futures price and the equality rate of Dollar to Iran Currency have correlated movement in majority of nine transaction periods (Seven transaction periods). Here, the alternative hypothesis, a significant correlation between FX and GCF, is confirmed by the result of bivariate correlation measure in seven transaction periods. It is interpreted that the foreign exchange rate, the equality rate of dollar to Iran currency, is one of determinants to predict the gold coin futures price.

\subsection{A regression analysis}

Based on the results of this study we realize that it is possible to setup a linear regression function to predict gold coin futures of this study. The proposed regression model of this paper has the following form,

$G C F=\beta_{0}+\beta_{1} G C+\beta_{2} G G+\beta_{3} F X+\beta_{4} t+\varepsilon$,

where $\beta_{0}$ to $\beta_{4}$ are the coefficient which are estimated, GC, GG, FX and $t$ are the independent variables which represent gold coin price, global gold price, foreign exchange and time, respectively. In addition, GCF and $\varepsilon$ represent the gold coin future and the residual for the regression estimation, respectively. We have divided the data in two different groups and the regression models have been estimated using ordinary least square technique. The first group is associated with the data where GCF is less or equal to than 2,400,000 Rials. The results are summarized as follows, 


$$
G C F=1,644,000+0.935 G C-0.272 G G-153.619 F X+32747.863 t+\varepsilon
$$

$$
\begin{array}{lllll}
\mathrm{t} \text {-student (12.0743) (22.205) (-12.117) } & (-10.436) & \text { (22.298) } & \overline{\mathrm{R}}^{2}=0.91
\end{array}
$$

As we can observe from Eq. (2), all t-student values confirm the results and $\bar{R}^{2}=0.91$ means that the regression model could predict gold coin future with more than $91 \%$ of accuracy. According to Eq. (2), a $1 \%$ increase on gold coin will result to a $0.935 \%$ increase on gold coin future. In addition, a one percent increase on foreign exchange would result to $-.272 \%$ decrease in gold coin future. We also expect a decline on gold coin future as the foreign exchange, US\$, increases. The second model, which represents the regression model when GCF is more than 2,400,000 Rials is as follows,

$$
G C F=11,190,000+1.066 G C-1167.073 F X+42414.702 t+\varepsilon
$$

$\mathrm{t}$ - student (7.338) (14.508) (-7.536) (4.828) $\quad \overline{\mathrm{R}}^{2}=0.649$

Again, we observe that t-values are all valid when the level of uncertainty is one percent and the regression could estimate approximately $65 \%$ of gold coin futures value. According to Eq. (3) a one percent increase on gold coin price could increase 1.066 percent on gold coin futures price. However, as foreign exchange, US\$, price increases we expect a decrease on gold coin futures price. The time has a positive impact on gold coin futures price.

\section{Conclusions}

In this paper, we have presented some regression functions to estimate gold coin futures price based on gold coin price, future exchange price, price of gold traded globally and trend of time. The proposed model of this paper was used for price estimation of special gold coin traded in Iran. The results have suggested that an increase on gold coin futures could increase gold coin futures price. An increase on foreign exchange price has negative impact on gold coin futures and present trend on time has positive impact on gold coin futures.

\section{References}

Aggarwal, R., \& Lucey, B. M. (2007). Psychological barriers in gold prices?. Review of Financial Economics, 16(2), 217-230.

Batten, J. A., Ciner, C., \& Lucey, B. M. (2010). The macroeconomic determinants of volatility in precious metals markets. Resources Policy, 35(2), 65-71.

Blose, L. E. (2010). Gold prices, cost of carry, and expected inflation. Journal of Economics and Business, 62(1), 35-47.

Mamon, R. S., Erlwein, C., Gopaluni, R. B. (2008). Adaptive signal processing of asset price dynamics with predictability analysis. Information Sciences, 178(1), 203-219.

Parisi, A., Parisi, F., \& Díaz, D. (2008). Forecasting gold price changes: Rolling and recursive neural network models. Journal of Multinational Financial Management, 18(5), 477-487.

Shafiee, S., \& Topal, E. (2010). An overview of global gold market and gold price forecasting. Resources Policy, 35(3), 178-189.

Tully, E., \& Lucey, B. M. (2007). A power GARCH examination of the gold market. Research in International Business and Finance, 21(2), 316-325.

Zhang, Y. J., \& Wei, Y. M. (2010). The crude oil market and the gold market: Evidence for cointegration, causality and price discovery. Resources Policy, 35(3), 168-177. 